\title{
Effect of haloxyfop and cerulenin on de novo biosynthesis of lipids in roots of wheat and maize
}

\author{
Walentyna Banaś ${ }^{\bowtie}$, Tomasz Furmanek² and Antoni Banaśs \\ IInstitute of Biology, University of Natural Sciences and Humanities, Siedlce, Poland; 2 Institute of Biology and Environmental Protection, Pomera- \\ nian University in Słupsk, Słupsk, Poland; ${ }^{3}$ ntercollegiate Faculty of Biotechnology of the University of Gdańsk and the Medical University of \\ Gdańsk, Gdańsk, Poland
}

The study examines the effects of haloxyfop (herbicide) and cerulenin (antibiotic) on de novo biosynthesis of fatty acids and complex lipids in roots of two sensitive species: wheat and maize. Seedlings were grown in hydroponic cultures with addition of $\left[1-{ }^{14} \mathrm{C}\right]$ acetate (control) and $\left[1-{ }^{14} \mathrm{C}\right]$ acetate together with one of the tested substances. Neither haloxyfop nor cerulenin prevented the uptake of $\left[{ }^{1-14} \mathrm{C}\right]$ acetate by the roots of tested species. In contrast, a strong inhibition of de novo biosynthesis of fatty acids was observed after a 4-h treatment. This phenomenon, however, tended to disappear with treatment time. After a 24-h incubation, the amount of radioactivity in de novo biosynthesized fatty acids in $1-\mathrm{cm}$-long root tips was up to three times higher than in the untreated control. In the "rest of roots", restoration of fatty acid biosynthesis capacity was less pronounced. Besides the effect on fatty acid biosynthesis, both tested inhibitors strongly suppressed the de novo biosynthesis of non-fatty acid-containing lipids. Analyses of radioactivity in individual lipid classes showed that after a 4-h treatment with haloxyfop or cerulenin the biosynthesis of most of the lipid classes was inhibited, although not to the same extent. After a 24-h treatment, an inhibition of de novo biosynthesis of some of the lipids was still observable, whereas the biosynthesis of others, especially phosphatidylethanolamine and phosphatidic acid, was strongly up-regulated. Contrary to the mainstream view that inhibition of fatty acid biosynthesis is the cause of haloxyfop and cerulenin phytotoxicity, the obtained results suggest multidirectional effects of both inhibitors.

Key words: cerulenin, graminicides, haloxyfop, fatty acids

Received: 12 February, 2012; revised: 17 July, 2012; accepted: 29 October, 2012; available on-line: 08 November, 2012

\section{INTRODUCTION}

Graminicides account for about $10 \%$ of the total herbicide market (Harwood, 1999). They are used for selective control of grass species in broad-leaved crops. Derivatives of aryloxyphenoxypropionic acid (e.g., haloxyfop) and derivatives of cyclohexanediones (e.g., alloxydim) belong to this herbicide family (Nestler, 1982; Cobb, 1992). Although they have been introduced into agriculture in mid-1980s, their plant annihilation mechanism remains controversial (De Prado et al, 1999; Shimabukuro et al, 2001; Luo et al, 2004). The mechanism of action of these herbicides was investigated most intensively during the last two decades of the twentieth century, when two competitive hypotheses were formulated.
The first one (most popular) claims that the inhibition of lipid biosynthesis is the main reason of the phytotoxicity of graminicides. Acetyl-CoA carboxylase, the key enzyme in fatty acid biosynthesis, was regarded as a target for graminicide action. In contrast to most of dicotyledonous plants, which contain in their plastids a multiprotein complex of ACCase insensitive to graminicides, grasses contain a sensitive, multifunctional form of ACCase (Lichtenthaler, 1990; Cobb, 1992; Tardif et al, 1996; Heap \& Morrison, 1986; Shukla et al, 1997). Alternative hypotheses claim that graminicides stimulate overproduction of free radicals causing plant death due to numerous damaging reactions known as "oxidative stress" (Banaś et al, 1993a; Shimabukuro \& Hoffer, 1996; Shimabukuro et al, 2001; Luo et al, 2004). This hypothesis was supported by (among others) experiments with graminicide antagonists which could act as free radical scavengers. Banaś et al (1993a, 1993b) demonstrated that inhibition of wheat roots growth caused by haloxyfop or alloxydim was partly or completely reduced by addition of genistein, propyl gallate, or diphenylamine to the growth medium. Shimabukuro et al (2001) proved the antagonistic effect of vitamin $\mathrm{E}$ on diclofop-methyl activity, and Luo et al (2004) showed antagonistic effect of vitamin $\mathrm{E}$ and ethoxyquin on fluazifop-butyl activity. The body of evidence supporting each of the hypotheses is, however, only fragmentary.

In our earlier work, we demonstrated that it was not always possible to observe the inhibitory effect of graminicides on de novo lipid biosynthesis in vivo. Young parts of wheat leaves treated for $48 \mathrm{hrs}$ with haloxyfopethoxyethyl incorporated ${ }^{14} \mathrm{C}$-labelled acetate into the lipid fraction at a similar rate as the control, despite the fact that the growth of the treated plants was completely inhibited (Banaś et al, 1990). In the root tips of wheat seedlings grown for $24 \mathrm{~h}$ with haloxyfop and ${ }^{14} \mathrm{C}$-labelled acetate, the amount of radioactivity in the lipid fraction was much higher than in the controls grown without the herbicide (Banaś et al, 1993c). In contrast to the mentioned results, when isolated plastids from wheat roots, or isolated chloroplasts from oat leaves were incubated with ${ }^{14} \mathrm{C}$-labelled acetate and the herbicide haloxyfop, a

e-mail: wbanas@uph.edu.pl

Abbreviations: ACCase, acetyl-CoA carboxylase; butyl PBD, 2-(tertButylphenyl)-5-(4-phenylphenyl)-1,3,4-oxadiazole; DAG, diacylglycerol; DGDG, digalactosyldiacylglycerol; FA, free fatty acids; LPE, lysophosphatidylethanolamine; PA, phosphatidic acid; PC, phosphatidylcholine; PE, phosphatidylethanolamine; PG, phosphatidylglycerol; PI, phosphatidylinositol; PS, phosphatidylserine; TAG, triacylglycerol; S, free sterols; SE, sterol esters. 
Table 1. Effect of haloxyfop and cerulenin on growth of wheat and maize roots

\begin{tabular}{lllllll}
\hline \multirow{2}{*}{ Tested species } & \multicolumn{5}{l}{ Increase in root length [mm] } \\
\cline { 2 - 7 } & \multicolumn{7}{l}{ 4-h treatment } & \multicolumn{4}{l}{ 24-h treatment } \\
\cline { 2 - 7 } & $\mathrm{C}$ & $\mathrm{H}$ & $\mathrm{Cer}$ & $\mathrm{C}$ & $\mathrm{H}$ & Cer \\
\hline Wheat & $4 \pm 1$ & $3 \pm 1(75)$ & $4 \pm 1(100)$ & $24 \pm 2$ & $12^{\mathrm{a}} \pm 2(50)$ & $13^{\mathrm{a}} \pm 2(54)$ \\
Maize & $3 \pm 1$ & $2^{\mathrm{a} \pm 1(67)}$ & $3 \pm 1(100)$ & $26 \pm 6$ & $13^{\mathrm{a}} \pm 2(50)$ & $16^{\mathrm{a}} \pm 2(62)$ \\
\hline
\end{tabular}

C, control; H, haloxyfop (wheat $\left[10^{-7} \mathrm{M}\right]$, maize $\left[3 \times 10^{-8} \mathrm{M}\right]$ ); Cer, cerulenin $\left[10^{-5} \mathrm{M}\right]$. Means \pm S.D. shown. Figures in parentheses show $\%$ of control values. a, significant difference between control and treated plants in mean difference two-sided test at $\alpha=0.05$

clear inhibition of de novo biosynthesis of fatty acids was observed (Banaś et al, 1993c).

In the present experiments, the effects of a herbicide, haloxyfop and an antibiotic, cerulenin (two different potential inhibitors of fatty acid biosynthesis) were investigated. Roots of two sensitive grass species (wheat and maize) were treated with those inhibitors over different time periods and the effects of those inhibitors on $d e$ novo biosynthesis of fatty acids and complex lipids were studied in detail.

\section{MATERIALS AND METHODS}

Plant material. The experiments were carried out on two species sensitive to graminicides: wheat (Triticum aestivum L. cv. Kadet) and maize (Zea mays L. cv. Concord). The grains were soaked in water for $18 \mathrm{~h}$ and sown on moist filter paper. After a 48-h germination in a dark growth chamber (wheat $21^{\circ} \mathrm{C}$, maize $25^{\circ} \mathrm{C}$ ), seedlings with $22-26 \mathrm{~mm}$ long central root were selected. The length of the central root was measured and subsequently, the seedlings were transferred to a nutrient solution (for composition see: (Nilsson, 1977)) with addition of $1.9 \times 10^{-4} \mathrm{M}\left[1-^{14} \mathrm{C}\right]$ acetate (sp. activity $0.1 \mu \mathrm{Ci} / 63 \mathrm{nmol}$; Sigma-Aldrich) only (control), or to the nutrient solution with addition of [1$\left.{ }^{14} \mathrm{C}\right]$ acetate and one of the tested substances - haloxyfop $\left(10^{-7} \mathrm{M}\right.$ for wheat and $3 \times 10^{-8} \mathrm{M}$ for maize; supplied in the acid form by Dow Chemical Company), or cerulenin $\left(10^{-5} \mathrm{M}\right.$ in all experiments; SigmaAldrich). The seedlings were placed in holes drilled in cork discs floating on the solution and incubated in the dark (wheat $21^{\circ} \mathrm{C}$, maize $25^{\circ} \mathrm{C}$ ). At the end of the experiments, the roots were rinsed in distilled water and the length of the central root was measured again (the increase in length was used as a measure of root growth).

Analysis of incorporation and distribution of labelled acetate. For each single analysis 10 wheat or 5 maize roots were used. Each root was divided into 1-cm-long tip and the rest of the root. Both parts were analysed separately. They were homogenized in a glass homogenizer with $3.75 \mathrm{ml}$ of chloroform/methanol $(1: 2, \mathrm{v} / \mathrm{v})$ and the extracts were transferred to glass tubes to which $1.25 \mathrm{ml}$ of $0.15 \mathrm{M}$ acetic acid, $1.25 \mathrm{ml}$ of chloroform, and $1.25 \mathrm{ml}$ of water were added; tubes were vigorously shaken and then centrifuged for $3 \mathrm{~min}(1000 \times g)$. The lower chloroform fraction contained lipids and the upper methanol/water fraction - polar compounds (Blight \& Dyer, 1959). Aliquots of both fractions were subsequently used for the measurement of total radioactivity. In the next step, the rests of chloroform fractions were used for further analysis and the methanol/water fractions were discarded.

Each remaining chloroform fraction was further divided into two parts. One was evaporated to dryness and methylated for $60 \mathrm{~min}$ at $90^{\circ} \mathrm{C}$ with $2 \% \mathrm{H}_{2} \mathrm{SO}_{4}$ in dry methanol. Next, $3 \mathrm{ml}$ of hexane and $2 \mathrm{ml}$ of water were added. After shaking and centrifugation, the hexane fractions were evaporated to dryness, dissolved in small amount of hexane and separated by TLC on precoated silica gel plates (Merck silica gel 60) with hexane:diethyl ether:acetic acid (70:30:1 by volume). The second part of each chloroform fraction, was also evaporated to dryness, dissolved in small amount of chloroform and directly separated by TLC with chloroform:methanol:acetic acid:water (170:30:20:7). The fatty acid methyl esters and other lipids were identified by comparing with standards run in parallel.

Total radioactivity in the chloroform and methanol/ water fractions was determined on LKB Wallace 1214 Rackbeta scintillation counter using a toluene/ethanol scintillation cocktail (2:1 by volume + butyl PBD $4 \mathrm{~g} / \mathrm{l})$. The radioactive lipids were visualised and quantified on the TLC plates by electronic autoradiography (Instant Imager, Packard Instrument Co).

All experiments were repeated at least three times.

Table 2. Effect of haloxyfop and cerulenin on [1-14C]acetate uptake (sum of radioactivity in methanol/water and chloroform fractions) by wheat and maize roots

\begin{tabular}{|c|c|c|c|c|c|c|c|}
\hline \multirow{3}{*}{$\begin{array}{l}\text { Tested } \\
\text { species }\end{array}$} & \multirow{3}{*}{ Part of root } & \multicolumn{6}{|c|}{ Total uptake [d.p.m. $\times 10^{-5} / 10$ roots (wheat) or $/ 5$ roots (maize)] } \\
\hline & & \multicolumn{3}{|c|}{ 4-h treatment } & \multicolumn{3}{|c|}{ 24-h treatment } \\
\hline & & C & $\mathrm{H}$ & Cer & C & $\mathrm{H}$ & Cer \\
\hline \multirow{3}{*}{ Wheat } & $1 \mathrm{~cm} \mathrm{tip}$ & $2.6 \pm 0.1$ & $2.2 \pm 0.3(85)$ & $2.3 \pm 0.3(88)$ & $3.1 \pm 0.9$ & $4.8^{a} \pm 0.2(155)$ & $3.5 \pm 0.4(113)$ \\
\hline & rest of root & $2.5 \pm 0.6$ & $2.6 \pm 0.9(104)$ & $2.3 \pm 0.2(92)$ & $11.7 \pm 1.6$ & $6.3^{\mathrm{a}} \pm 0.5(54)$ & $7.0^{a} \pm 0.4(60)$ \\
\hline & $\begin{array}{l}\text { average } 1 \mathrm{~cm} \\
\text { of rest of root }\end{array}$ & $1.2 \pm 0.3$ & $1.3 \pm 0.5(108)$ & $1.2 \pm 0.1(100)$ & $2.9 \pm 0.4$ & $2.3 \pm 0.1(79)$ & $2.4 \pm 0.1(83)$ \\
\hline \multirow{3}{*}{ Maize } & $1 \mathrm{~cm}$ tip & $1.3 \pm 0.2$ & $1.4 \pm 0.2(108)$ & $1.5 \pm 0.2(115)$ & $2.3 \pm 0.4$ & $3.1^{\mathrm{a}} \pm 0.3(135)$ & $3.0 \pm 0.6(130)$ \\
\hline & rest of root & $1.7 \pm 0.2$ & $1.8 \pm 0.3(106)$ & $1.7 \pm 0.4(100)$ & $11.4 \pm 2.1$ & $8.8 \pm 1.1(77)$ & $8.4 \pm 1.9(74)$ \\
\hline & $\begin{array}{l}\text { average } 1 \mathrm{~cm} \\
\text { of rest of root }\end{array}$ & $0.8 \pm 0.1$ & $0.9 \pm 0.2(113)$ & $0.9 \pm 0.2(113)$ & $2.6 \pm 0.5$ & $2.7 \pm 0.2(104)$ & $2.7 \pm 0.6(104)$ \\
\hline
\end{tabular}

C, control; H, haloxyfop (wheat $\left[10^{-7}\right.$ M]. maize $\left[3 \times 10^{-8} \mathrm{M}\right]$ ); Cer,. cerulenin $\left[10^{-5} \mathrm{M}\right]$. Means \pm S.D. shown ( $\mathrm{n} \geq 3$ ). Figures in parentheses show \% of control values. a, significant difference between control and treated plants in mean difference two-sided test at $\alpha=0.05$ 
Table 3. Effect of haloxyfop and cerulenin on incorporation of $[1-14 \mathrm{C}]$ acetate into fatty acids of wheat and maize roots

\begin{tabular}{|c|c|c|c|c|c|c|c|}
\hline \multirow{3}{*}{$\begin{array}{l}\text { Tested } \\
\text { species }\end{array}$} & \multirow{3}{*}{ Part of root } & \multicolumn{6}{|c|}{ Radioactivity in fatty acids [d.p.m. $\times 10^{-4} / 10$ roots (wheat) or $/ 5$ roots (maize)] } \\
\hline & & \multicolumn{3}{|c|}{ 4-h treatment } & \multicolumn{3}{|l|}{ 24-h treatment } \\
\hline & & C & $\mathrm{H}$ & Cer & $\mathrm{C}$ & $\mathrm{H}$ & Cer \\
\hline \multirow{3}{*}{ Wheat } & $1 \mathrm{~cm}$ tip & $\begin{array}{l}4.4 \pm 0.3 \\
{[17]}\end{array}$ & $\begin{array}{l}1.7^{a} \pm 0.7\left[9^{a}\right] \\
(37)\end{array}$ & $\begin{array}{l}1.9^{a} \pm 0.6\left[8^{a}\right] \\
(43)\end{array}$ & $3.5 \pm 1.3[11]$ & $\begin{array}{l}10.8^{a} \pm 0.8\left[23^{a}\right] \\
(309)\end{array}$ & $\begin{array}{l}5.5 \pm 0.8[16] \\
(157)\end{array}$ \\
\hline & rest of root & $\begin{array}{l}4.4 \pm 1.0 \\
{[18]}\end{array}$ & $\begin{array}{l}1.9^{a} \pm 0.9\left[9^{a}\right] \\
(43)\end{array}$ & $\begin{array}{l}2.6^{\mathrm{a}} \pm 0.8\left[11^{\mathrm{a}}\right] \\
(59)\end{array}$ & $28.4 \pm 1.8[24]$ & $\begin{array}{l}23.0^{\mathrm{a}} \pm 1.2\left[37^{\mathrm{a}}\right] \\
(81)\end{array}$ & $\begin{array}{l}19.8^{\mathrm{a}} \pm 1.9[28] \\
(70)\end{array}$ \\
\hline & $\begin{array}{l}\text { average } 1 \mathrm{~cm} \\
\text { of rest of root }\end{array}$ & $2.2 \pm 0.25$ & $\begin{array}{l}1.2^{a} \pm 0.5 \\
(55)\end{array}$ & $\begin{array}{l}1.5^{a} \pm 0.5 \\
(68)\end{array}$ & $6.3 \pm 0.6$ & $\begin{array}{l}9.1^{\mathrm{a}} \pm 0.5 \\
(144)\end{array}$ & $6.5 \pm 0.6(103)$ \\
\hline \multirow{3}{*}{ Maize } & $1 \mathrm{~cm}$ tip & $\begin{array}{l}3.2 \pm 0.6 \\
{[26]}\end{array}$ & $\begin{array}{l}2.4^{\mathrm{a}} \pm 0.2\left[17^{\mathrm{a}}\right] \\
(75)\end{array}$ & $\begin{array}{l}2.0^{\mathrm{a}} \pm 0.1\left[14^{\mathrm{a}}\right] \\
(62)\end{array}$ & $3.3 \pm 1.6[15]$ & $\begin{array}{l}5.6^{\mathrm{a}} \pm 0.3[18] \\
(170)\end{array}$ & $\begin{array}{l}5.7^{a} \pm 0.6[22] \\
(173)\end{array}$ \\
\hline & rest of root & $\begin{array}{l}4.8 \pm 0.9 \\
{[27]}\end{array}$ & $\begin{array}{l}2.2^{\mathrm{a}} \pm 0.3\left[13^{\mathrm{a}}\right] \\
(46)\end{array}$ & $\begin{array}{l}1.9^{\mathrm{a}} \pm 0.2\left[12^{\mathrm{a}}\right] \\
(40)\end{array}$ & $32.7 \pm 8.2[30]$ & $\begin{array}{l}26.5 \pm 2.8[30] \\
(81)\end{array}$ & $\begin{array}{l}14.5^{\mathrm{a}} \pm 2.0\left[20^{\mathrm{a}}\right] \\
(44)\end{array}$ \\
\hline & $\begin{array}{l}\text { average } 1 \mathrm{~cm} \\
\text { of rest of root }\end{array}$ & $2.3 \pm 0.4$ & $\begin{array}{l}1.0^{a} \pm 0.1 \\
(43)\end{array}$ & $\begin{array}{l}1.0^{\mathrm{a}} \pm 0.1 \\
(43)\end{array}$ & $7.4 \pm 1.2$ & $\begin{array}{l}8.0 \pm 0.8 \\
(108)\end{array}$ & $4.7^{a} \pm 0.6(64)$ \\
\hline
\end{tabular}

$\mathrm{C}$, control; H, haloxyfop (wheat $\left[10^{-7} \mathrm{M}\right]$, maize $\left[3 \times 10^{-8} \mathrm{M}\right]$ ); Cer, cerulenin $\left[10^{-5} \mathrm{M}\right]$. Means \pm S.D. shown (n $\geq 3$ ). Figures in square parentheses show $\%$ of total radioactivity in fatty acids; figures in parentheses show $\%$ of control values. a, significant difference between control and treated plants in mean difference two-sided test at $\alpha=0.05$

\section{RESULTS}

The aim of preliminary experiments with non-radioactive acetate was to identify concentrations of haloxyfop and cerulenin that would be sufficient to cause about $50 \%$ inhibition of root growth during a 24-h treatment. It appeared that such growth inhibition of maize and wheat roots was achieved by using respectively $3 \times 10^{-8}$ $\mathrm{M}$ and $10^{-7} \mathrm{M}$ haloxyfop. Cerulenin inhibited root elongation less efficiently and could only produce similar results as haloxyfop in at least 100 times higher concentrations $\left(10^{-5} \mathrm{M}\right)$. The inhibition of root elongation by haloxyfop was observable already after a 4 -h treatment. The inhibitory effect of cerulenin was observable only after longer periods. In experiments with $\left[1-{ }^{14} \mathrm{C}\right]$ acetate the same/very similar inhibition of root growth (by haloxyfop and cerulenin) was observed as in experiments with non-labelled acetate (Table 1). During the first $4 \mathrm{~h}$ of treatment neither haloxyfop nor cerulenin significantly affected the uptake of ${ }^{14} \mathrm{C}$-labelled acetate by different parts of roots of both tested species. After 24 h of treatment, the amount of incorporated radioactivity in $1-\mathrm{cm}$ root tips of haloxyfop- and cerulenin-treated plants was higher than in the control (however, only in the case of haloxyfop the difference was statistically significant). In the root parts remaining after cutting off the 1 -cm-long tips, the incorporated amount of radioactivity was lower than in the control. However, the treated roots were shorter and the amount of incorporated radioactivity calculated per $1 \mathrm{~cm}$ of the "rest of root" did not differ significantly from the control (Table 2).

Only a fraction of the ${ }^{14} \mathrm{C}$-labelled acetate absorbed by the roots was used for de novo biosynthesis of fatty acids. The root tips of the control wheat and maize seedlings

Table 4. Effect of haloxyfop and cerulenin on incorporation of $\left[1-{ }^{14} \mathrm{C}\right]$ acetate into non-fatty acid-containing lipids of wheat and maize roots

\begin{tabular}{|c|c|c|c|c|c|c|c|}
\hline \multirow{3}{*}{$\begin{array}{l}\text { Tested } \\
\text { species }\end{array}$} & \multirow{3}{*}{ Part of root } & \multicolumn{6}{|c|}{$\begin{array}{l}\text { Radioactivity in non-fatty acid-containing lipids } \\
\text { [d.p.m. } \times 10^{-4} / 10 \text { roots (wheat) or } / 5 \text { roots (maize)] }\end{array}$} \\
\hline & & \multicolumn{3}{|l|}{ 4-h treatment } & \multicolumn{3}{|l|}{ 24-h treatment } \\
\hline & & C & $\mathrm{H}$ & Cer & C & $\mathrm{H}$ & Cer \\
\hline \multirow{3}{*}{ Wheat } & $1 \mathrm{~cm}$ tip & $9.6 \pm 1.2[37]$ & $\begin{array}{l}5.9^{\mathrm{a}} \pm 0.3\left[26^{\mathrm{a}}\right] \\
(61)\end{array}$ & $\begin{array}{l}6.9^{a} \pm 0.8[30] \\
(72)\end{array}$ & $11.4 \pm 1.3[37]$ & $\begin{array}{l}17.6^{\mathrm{a}} \pm 1.2[37] \\
(154)\end{array}$ & $\begin{array}{l}15.0 \pm 1.2\left[43^{\mathrm{a}}\right] \\
(132)\end{array}$ \\
\hline & rest of root & $4.9 \pm 1.0[24]$ & $\begin{array}{l}3.1^{\mathrm{a}} \pm 0.7\left[10^{\mathrm{a}}\right] \\
(63)\end{array}$ & $\begin{array}{l}2.7^{\mathrm{a}} \pm 0.3\left[12^{\mathrm{a}}\right] \\
(55)\end{array}$ & $38.1 \pm 2.4[33]$ & $\begin{array}{l}12.4^{\mathrm{a}} \pm 4.1\left[20^{\mathrm{a}}\right] \\
(33)\end{array}$ & $\begin{array}{l}15.1^{\mathrm{a}} \pm 1.9\left[22^{\mathrm{a}}\right] \\
(40)\end{array}$ \\
\hline & $\begin{array}{l}\text { average } 1 \mathrm{~cm} \\
\text { of rest of root }\end{array}$ & $2.5 \pm 0.5$ & $\begin{array}{l}1.6^{\mathrm{a}} \pm 0.3 \\
(64)\end{array}$ & $\begin{array}{l}1.4^{\mathrm{a}} \pm 0.2 \\
(56)\end{array}$ & $9.3 \pm 0.6$ & $\begin{array}{l}4.6^{a} \pm 1.5 \\
(49)\end{array}$ & $\begin{array}{l}5.2^{\mathrm{a}} \pm 0.2 \\
(56)\end{array}$ \\
\hline \multirow{3}{*}{ Maize } & $1 \mathrm{~cm}$ tip & $4.5 \pm 0.8[35]$ & $\begin{array}{l}3.8 \pm 0.7[29] \\
(84)\end{array}$ & $\begin{array}{l}4.6 \pm 0.6[31] \\
(102)\end{array}$ & $7.3 \pm 3.6[31]$ & $\begin{array}{l}12.0^{\mathrm{a}} \pm 1.7[38] \\
(164)\end{array}$ & $\begin{array}{l}8.9 \pm 4.8[31] \\
(122)\end{array}$ \\
\hline & rest of root & $2.3 \pm 0.8[12]$ & $\begin{array}{l}1.3^{\mathrm{a}} \pm 0.2[8] \\
(57)\end{array}$ & $\begin{array}{l}1.3^{\mathrm{a}} \pm 0.4[8] \\
(57)\end{array}$ & $33.0 \pm 6.6[29]$ & $\begin{array}{l}17.8^{\mathrm{a}} \pm 3.5\left[20^{\mathrm{a}}\right] \\
(54)\end{array}$ & $\begin{array}{l}17.2^{\mathrm{a}} \pm 5.4\left[22^{\mathrm{a}}\right] \\
(52)\end{array}$ \\
\hline & $\begin{array}{l}\text { average } 1 \mathrm{~cm} \\
\text { of rest of root }\end{array}$ & $1.1 \pm 0.4$ & $\begin{array}{l}0.6^{a} \pm 0.1 \\
(55)\end{array}$ & $\begin{array}{l}0.7 \pm 0.2 \\
(64)\end{array}$ & $7.4 \pm 1.8$ & $\begin{array}{l}6.9 \pm 0.9 \\
(93)\end{array}$ & $\begin{array}{l}6.4 \pm 2.2 \\
(86)\end{array}$ \\
\hline
\end{tabular}

$\mathrm{C}$, control; $\mathrm{H}$, haloxyfop (wheat $\left[10^{-7} \mathrm{M}\right]$, maize $\left[3 \times 10^{-8} \mathrm{M}\right]$ ); Cer, cerulenin $\left[10^{-5} \mathrm{M}\right]$. Means $\pm \mathrm{S} . \mathrm{D}$ shown (n $\geq 3$ ). Figures in square parentheses show $\%$ of total radioactivity in non-fatty acid containing lipids; figures in parentheses show $\%$ of control values. a, significant difference between control and treated plants in mean difference two-sided test at $\alpha=0.05$ 
Table 5. Effect of haloxyfop and cerulenin on incorporation of [1-14C]acetate into lipids (containing and not containing fatty acids) of wheat roots

\begin{tabular}{|c|c|c|c|c|c|c|c|c|c|c|c|c|c|c|}
\hline \multirow{2}{*}{$\begin{array}{l}\text { Treat- } \\
\text { ment } \\
\text { time } \\
\text { (hrs) }\end{array}$} & \multirow[b]{2}{*}{$\begin{array}{l}\text { Part of } \\
\text { root }\end{array}$} & \multirow[b]{2}{*}{$\begin{array}{l}\text { Treat- } \\
\text { ment }\end{array}$} & \multicolumn{12}{|c|}{ Radioactivity in different lipids (C, d.p.m. x 10-3 /10 roots; $\mathrm{H}$ and Cer, $\%$ of control values) } \\
\hline & & & $\begin{array}{l}\text { SE } \\
\text { TAG } \\
\text { DAG }\end{array}$ & $\begin{array}{l}\mathrm{FA} \\
\mathrm{S}\end{array}$ & $X_{1}$ & $X_{2}$ & PA & $Y_{1}$ & $\mathrm{Y}_{2}$ & PE & PG & $\begin{array}{l}\mathrm{PC} \\
\mathrm{DGDG}\end{array}$ & PS & $\begin{array}{l}\text { PI } \\
\text { LPE }\end{array}$ \\
\hline \multirow{6}{*}{4} & \multirow{3}{*}{$\begin{array}{l}1 \mathrm{~cm} \\
\text { tips }\end{array}$} & $\mathrm{C}$ & 26.6 & 64.4 & 7.0 & 5.7 & 1.3 & 1.8 & 12.7 & 6.9 & 1.4 & 8.4 & 2.5 & 0.4 \\
\hline & & $\mathrm{H}$ & 57 & 59 & 40 & 31 & 54 & 46 & 53 & 24 & 43 & 57 & 66 & 91 \\
\hline & & Cer & 70 & 71 & 38 & 14 & 63 & 48 & 28 & 56 & 75 & 65 & 38 & 105 \\
\hline & \multirow{3}{*}{$\begin{array}{l}\text { average } \\
1 \mathrm{~cm} \\
\text { of rest of } \\
\text { root }\end{array}$} & $C$ & 6.6 & 17.4 & 5.6 & 3.5 & 0.5 & 0.3 & 2.8 & 4.0 & 0.9 & 2.9 & 1.4 & 1.2 \\
\hline & & $\mathrm{H}$ & 59 & 57 & 45 & 32 & 40 & 47 & 59 & 65 & 72 & 46 & 64 & 90 \\
\hline & & Cer & 41 & 64 & 30 & 48 & 62 & 57 & 35 & 61 & 86 & 69 & 57 & 137 \\
\hline \multirow{6}{*}{24} & \multirow{3}{*}{$\begin{array}{l}1 \mathrm{~cm} \\
\text { tips }\end{array}$} & $C$ & 23.8 & 81.9 & 3.7 & 1.0 & 2.5 & 1.9 & 9.4 & 8.9 & 2.1 & 5.2 & 1.6 & 0.6 \\
\hline & & $\mathrm{H}$ & 203 & 118 & 114 & 109 & 494 & 131 & 139 & 667 & 489 & 218 & 294 & 331 \\
\hline & & Cer & 198 & 105 & 126 & 177 & 365 & 74 & 39 & 298 & 235 & 177 & 88 & 172 \\
\hline & \multirow{3}{*}{$\begin{array}{l}\text { average } \\
1 \mathrm{~cm} \\
\text { of rest of } \\
\text { root }\end{array}$} & $C$ & 11.7 & 69.7 & 7.9 & 4.2 & 4.7 & 2.1 & 11.2 & 21.1 & 3.2 & 5.2 & 4.1 & 14.4 \\
\hline & & $\mathrm{H}$ & 63 & 40 & 41 & 25 & 61 & 44 & 28 & 236 & 226 & 84 & 101 & 146 \\
\hline & & Cer & 73 & 33 & 33 & 29 & 56 & 40 & 11 & 234 & 189 & 70 & 86 & 125 \\
\hline
\end{tabular}

C, control; $\mathrm{H}$, haloxyfop [10-7 M]; Cer, cerulenin [10-5 M]; standard deviation is not presented to improve readability of data (usually it was below $15 \%$ of the mean value) $X_{1}, X_{2}, Y_{1}, Y_{2}$, unidentified lipids

incorporated about 17 and $26 \%$ of the absorbed radioactivity, respectively, into fatty acids after 4-h incubation, with the amount falling to 11 and $15 \%$ respectively, after $24 \mathrm{~h}$. The more mature parts of the roots (those remaining after cutting off the tips) utilised the ${ }^{14} \mathrm{C}$-labelled acetate for fatty acid biosynthesis more efficiently. In the case of wheat - about $18 \%$ and in the case of maize - $27 \%$ of the absorbed ${ }^{14} \mathrm{C}$-labelled acetate after a $4-\mathrm{h}$ incubation, and 24 and 30\%, respectively, after $24-\mathrm{h}$ incubation were used for fatty acid biosynthesis. The addition of haloxyfop or cerulenin to the incubation medium strongly inhibited the incorporation of $\left[{ }^{14} \mathrm{C}\right]$ acetate into fatty acids during the first $4 \mathrm{~h}$ of treatment. The inhi- bition was observable in both the absolute amount of radioactivity incorporated into de novo synthesised fatty acids, as well as in terms of the percentage of incorporated $\left[{ }^{14} \mathrm{C}\right]$ acetate used for fatty acid biosynthesis. In the case of wheat roots, a stronger inhibition was detected in root tips, whereas in maize roots — in the mature parts of roots (Table 3 ).

The inhibition of fatty acid biosynthesis, which was clearly visible following the first $4 \mathrm{~h}$ of haloxyfop and cerulenin treatment, showed a tendency to revers with treatment time. After a 24-h incubation, the absolute amount of $\left[{ }^{14} \mathrm{C}\right]$ acetate incorporated into fatty acids of 1 -cm-long tips of haloxyfop-treated wheat roots was in

Table 6. Effect of haloxyfop and cerulenin on incorporation of $\left[1-{ }^{14} \mathrm{C}\right]$ acetate into lipids (containing and not containing fatty acids) of maize roots

\begin{tabular}{|c|c|c|c|c|c|c|c|c|c|c|c|c|c|c|}
\hline \multirow{2}{*}{$\begin{array}{l}\text { Treat- } \\
\text { ment } \\
\text { time } \\
\text { (hrs) }\end{array}$} & \multirow[b]{2}{*}{$\begin{array}{l}\text { Part of } \\
\text { root }\end{array}$} & \multirow[b]{2}{*}{$\begin{array}{l}\text { Treat- } \\
\text { ment }\end{array}$} & \multicolumn{12}{|c|}{ Radioactivity in different lipids (C, d.p.m. $\times 10^{-3} / 5$ roots; $\mathrm{H}$ and $\mathrm{Cer}, \%$ of control values) } \\
\hline & & & $\begin{array}{l}\text { SE } \\
\text { TAG } \\
\text { DAG }\end{array}$ & $\begin{array}{l}\text { FA } \\
\text { S }\end{array}$ & $\mathrm{X}_{1}$ & $\mathrm{X}_{2}$ & PA & $Y_{1}$ & $\mathrm{Y}_{2}$ & PE & PG & $\begin{array}{l}\text { PC } \\
\text { DGDG }\end{array}$ & PS & $\begin{array}{l}\text { PI } \\
\text { LPE }\end{array}$ \\
\hline \multirow{6}{*}{4} & \multirow[t]{3}{*}{$1 \mathrm{~cm}$ tips } & C & 16.2 & 26.9 & 3.9 & 1.8 & 0.7 & 1.2 & 7.6 & 3.0 & 1.7 & 9.2 & 2.6 & 0.9 \\
\hline & & $\mathrm{H}$ & 88 & 90 & 68 & 59 & 72 & 64 & 64 & 95 & 81 & 74 & 83 & 74 \\
\hline & & Cer & 102 & 113 & 31 & 63 & 86 & 28 & 8 & 92 & 109 & 79 & 20 & 86 \\
\hline & \multirow{3}{*}{$\begin{array}{l}\text { average } 1 \\
\mathrm{~cm} \\
\text { of rest of } \\
\text { root }\end{array}$} & $C$ & 6.8 & 5.4 & 2.8 & 1.8 & 0.6 & 0.3 & 3.4 & 2.5 & 1.4 & 6.1 & 1.6 & 0.4 \\
\hline & & $\mathrm{H}$ & 49 & 62 & 48 & 28 & 32 & 31 & 45 & 44 & 45 & 54 & 46 & 33 \\
\hline & & Cer & 55 & 81 & 33 & 31 & 42 & 27 & 14 & 67 & 62 & 47 & 22 & 73 \\
\hline \multirow{6}{*}{24} & \multirow[t]{3}{*}{$1 \mathrm{~cm}$ tips } & $\mathrm{C}$ & 22.3 & 42.4 & 4.1 & 1.6 & 2.1 & 1.9 & 6.4 & 9.2 & 1.4 & 9.0 & 1.7 & 0.7 \\
\hline & & $\mathrm{H}$ & 190 & 162 & 77 & 111 & 540 & 111 & 144 & 185 & 319 & 127 & 155 & 143 \\
\hline & & Cer & 190 & 114 & 106 & 101 & 358 & 84 & 9 & 285 & 148 & 96 & 69 & 158 \\
\hline & \multirow{3}{*}{$\begin{array}{l}\text { average } 1 \\
\mathrm{~cm} \\
\text { of rest of } \\
\text { root }\end{array}$} & $C$ & 25.3 & 46.2 & 6.6 & 5.1 & 4.8 & 2.2 & 12.8 & 17.9 & 3.1 & 16.4 & 3.0 & 1.0 \\
\hline & & $\mathrm{H}$ & 85 & 73 & 72 & 71 & 115 & 66 & 66 & 165 & 152 & 66 & 112 & 64 \\
\hline & & Cer & 73 & 60 & 61 & 33 & 102 & 51 & 8 & 173 & 92 & 37 & 48 & 79 \\
\hline
\end{tabular}

$\mathrm{C}$, control; $\mathrm{H}$, haloxyfop $\left[3 \times 10^{-8} \mathrm{M}\right]$; Cer, cerulenin $\left[10^{-5} \mathrm{M}\right]$; standard deviation is not presented to improve readability of data (usually it was below $15 \%$ of the mean value) $X_{1}, X_{2}, Y_{1}, Y_{2}$, unidentified lipids 
fact 3 times higher than in the control, and 1.7 times higher in maize. The treatment with cerulenin resulted in an increase of radioactivity of root tip fatty acids of both tested species by slightly more than $50 \%$ over the values obtained for the control. In the rest of roots the absolute amount of radioactivity in fatty acids of the treated plants was always lower than in the control. However, when the absolute amount of incorporated radioactivity was divided by the length of the "rest of roots", only the cerulenin-treated maize roots showed a statistically significant inhibition of the de novo biosynthesis of fatty acids. The treatment of wheat roots with haloxyfop generated even a statistically significant increase (about 1.4 fold) of incorporation of $\left[{ }^{14} \mathrm{C}\right]$ acetate into fatty acids (Table 3$)$.

The 24-h treatment of wheat roots with haloxyfop resulted also in a statistically significant increase in utilisation of $\left[{ }^{14} \mathrm{C}\right]$ acetate absorbed by roots for fatty acid biosynthesis. In the case of root tips, the utilisation increased from $11 \%$ (control) to $23 \%$ (treated) of absorbed $\left[{ }^{14} \mathrm{C}\right]$ acetate, and in the "rest of roots" - from $24 \%$ to $37 \%$ respectively. Only the "rest of roots" of maize seedlings treated with cerulenin showed a statistically significant decrease in utilisation of $\left[{ }^{14} \mathrm{C}\right]$ acetate $\mathrm{ab}-$ sorbed by roots for fatty acid biosynthesis (Table 3).

Part of the $\left[{ }^{14} \mathrm{C}\right]$ acetate incorporated by roots was used for biosynthesis of lipids not containing fatty acids. Contrary to the de novo biosynthesis of fatty acids, a higher percentage of $\left[{ }^{14} \mathrm{C}\right]$ acetate was utilised for de novo biosynthesis of non-fatty acid-containing lipids in root tips (up to $43 \%$ ) than in the "rest of roots". Strong inhibition of de novo biosynthesis of these types of compounds occurred in the tips and the "rest of roots" of wheat seedlings treated for $4 \mathrm{~h}$ with haloxyfop or cerulenin. When a 24-h treatment with the inhibitors was used, the inhibition occurred only in the "rest of roots". In the case of maize roots treated with haloxyfop or cerulenin for 4 or $24 \mathrm{~h}$, the inhibition of de novo biosynthesis of nonfatty acid-containing lipids was visible only in the "rest of roots". However, only in the case of a 4-h treatment of maize roots with haloxyfop, the inhibition calculated per $1 \mathrm{~cm}$ length of the "rest of roots" was statistically significant (Table 4).

When chloroform fractions were separated on TLC and the radioactive lipids visualised and quantified by electronic autoradiography (as an example, see Fig. 1.), it appeared that the radioactivity was not distributed evenly among different lipid classes. In wheat up to $55 \%$, and in maize up to $46 \%$ of the radioactivity was found in the "S + FA" fraction. These lipids were synthesised de novo in higher quantities in the root tips of both plants, during $4 \mathrm{~h}$ of incubation, compared to the quantities in an average $1 \mathrm{~cm}$ of the "rest of roots". The difference was less pronounced after 24 $h$ of incubation, especially in the control plants. The second most radioactive lipid fraction after a 4-h incubation was "SE + TAG + DAG". However, after $24 \mathrm{~h}$ of incubation, the situation was not so clear. In some cases, other lipids (especially PE) contained more radioactivity than "SE + TAG + DAG", or even more than "S + FA" (average $1 \mathrm{~cm}$ of the "rest of roots" treated for $24 \mathrm{~h}$ with haloxyfop). The inhibitor used, as well as the incubation time, strongly influenced the distribution of radioactivity among different lipid classes localised on TLC below the "S + FA" fraction (polar lipids) (Tables 5 and 6).

Short treatment $(4 \mathrm{~h})$ with haloxyfop or cerulenin resulted in an inhibition of de novo biosynthesis of the majority of lipids. In wheat roots, the inhibition

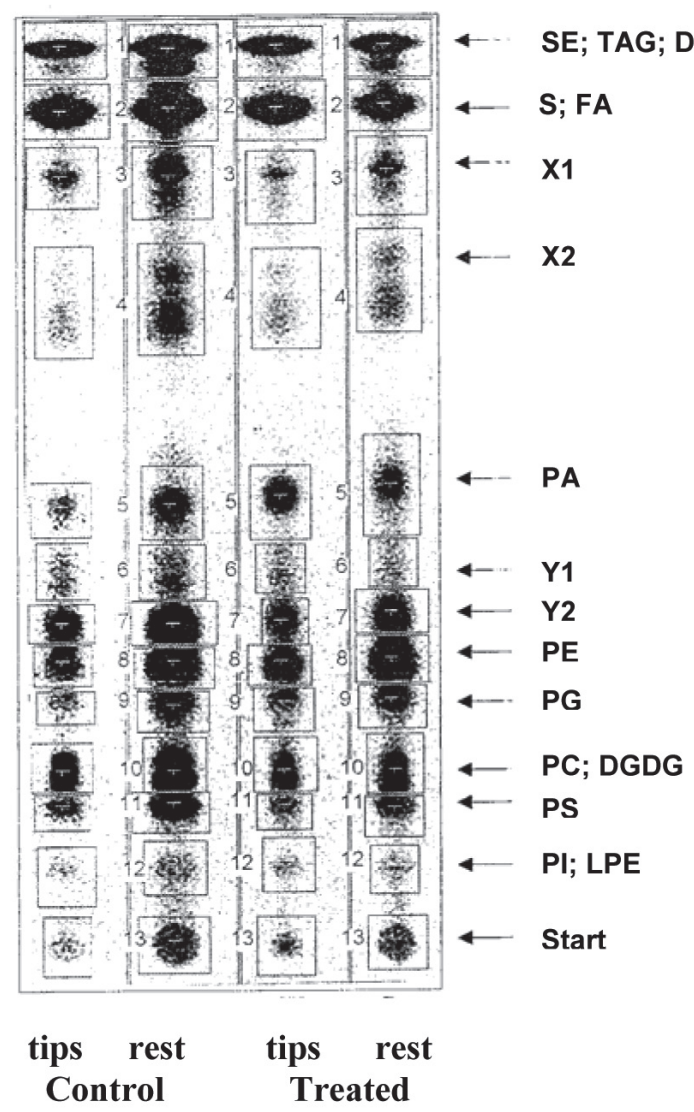

Figure 1. Autoradiogram of lipids of chloroform fractions from "tips" and "rests" of maize roots separated on TLC with chloroform: methanol: acetic acid: water (170:30:20:7).

The roots were grown for $24 \mathrm{hrs}$ in nutrient solution with $\left[1-{ }^{14} \mathrm{C}\right]$ acetate (control) and with $\left[1^{-14} \mathrm{C}\right]$ acetate $+3 \times 10^{-8} \mathrm{M}$ haloxyfop (treated). $X_{1}, X_{2}, Y_{1}, Y_{2}$, unidentified lipids

caused by haloxyfop was similar in root tips and in an average $1 \mathrm{~cm}$ of the "rest of roots". In maize, the inhibition was stronger in the "rest of roots". Generally, a similar tendency could also be observed in the roots treated with cerulenin. However, cerulenin had a weaker effect on biosynthesis of neutral lipids (in the tips of maize roots there was no inhibitory effect at all), but very strongly inhibited the synthesis of some of the polar lipids, especially an unidentified lipid, $\mathrm{Y}_{2}$ (probably cardiolipin) and PS (Tables 5 and 6).

After $24 \mathrm{~h}$ of treatment with haloxyfop or cerulenin, in the root tips of both wheat and maize seedlings the amount of radioactivity in the majority of lipids was higher than in the control. The strongest stimulatory effect was observed for the de novo biosynthesis of PE and PA. In contrast, in an average 1 $\mathrm{cm}$ of the "rest of roots", both haloxyfop and cerulenin inhibited the de novo biosynthesis of the majority of lipids, but the biosynthesis of some, especially PE and PG, was stimulated. In both plants, the average amount of radioactivity incorporated into polar lipids in an average $1 \mathrm{~cm}$ of the "rest of roots" was equal to or higher than in the control in the case of haloxyfop treatment and equal to or a bit lower than in the control in the case of cerulenin treatment. Similarly to the results of a 4-h treatment an incubation of the roots of both tested plants with cerulenine for $24 \mathrm{~h}$ caused a strong inhibition of an unidentified lipid, Y2 (Tables 5 and 6$)$. 


\section{DISCUSSION}

In the present study, $\left[{ }^{14} \mathrm{C}\right]$ acetate was used as a precursor for lipid biosynthesis. Already in 1982, Roughan and Slack (Roughan \& Slack, 1982) showed that this radiolabelled compound is a suitable and effective precursor for plant lipids. It was also utilised in other studies addressing the effect of graminicides on lipid biosynthesis (e.g., Hoppe, 1985; Banaś et al, 1990, 1993c; Price et al, 2003). Therefore, the results obtained in this work can be compared with earlier research.

The potential of graminicides to inhibit acetyl-CoA carboxylase (ACCase) is well-documented (Lichtenthaler, 1990; Cobb, 1992). The experimental data that we present suggests, however, that the inhibition of in vivo fatty acid biosynthesis could be only temporary. The reasons why plants treated with haloxyfop rebuild their capacity for fatty acids biosynthesis remain unknown. One possible explanation could be an increase, with the time of treatment, of the ability to detoxify haloxyfop in plastids, where fatty acids are synthesized. If this could occur, the fatty acid biosynthesis would be restored, as the inhibition of ACCase is reversible (Rendina et al, 1988). Another possibility could be the synthesis of a haloxyfopinsensitive (or less susceptible) acetyl-CoA carboxylase. So far, there is no evidence that the plastids of grasses have more than one isoform of this enzyme. It has been shown, however, that grasses do have isoforms of ACCase with different sensitivity to graminicides (Herbert et al, 1997).

The rebuilding of the capacity for fatty acid biosynthesis occurred also in plants treated with cerulenin. However, this process was less pronounced than in those treated with haloxyfop. Cerulenin is an inhibitor of fatty acid biosynthesis with a different mechanism of action than graminicides. It inhibits activity of type I of $\beta$-keto-acyl synthase, which is responsible for the condensation reactions of malonyl group with the growing acyl chain until it reaches the length of 16 carbons (Packter \& Stumpf, 1975; Feld et al, 1989). The reasons of why plants treated with cerulenin rebuild their capacity for biosynthesis of fatty acids could be similar as in the case of haloxyfop. Additionally, $\beta$-keto-acyl synthase type II and III could partially replace the type I inhibited by cerulenin. As fatty acids are absolutely essential for cell functioning, it seems reasonable to assume that in the course of evolution, several precautionary measures have been developed to prevent biosynthesis disruptions.

Regardless of the mechanism of restoration of fatty acid biosynthesis, the obtained results suggest that a shortage of de novo synthesised fatty acids is probably not the direct reason for haloxyfop's (and probably cerulenin's) phytotoxicity. However, one cannot exclude the possibility that the observed transient inhibition of fatty acid biosynthesis activates a cascade of events leading to accelerated ageing and subsequent death of susceptible plants.

Besides the above discussed impact on fatty acid biosynthesis, haloxyfop and cerulenin inhibited the incorporation of radiolabelled acetate into lipophilic compounds not containing fatty acids. To what extent the inhibition of biosynthesis of those compounds contributes to the phytotoxic effects of the tested inhibitors remains, however, open to further investigation.

The use of electronic autoradiography in this study allowed a detailed determination of the location of radioactive compounds on chromatograms. Additionally, it was possible to specify the utilisation of $\left[{ }^{14} \mathrm{C}\right]$ acetate absorbed by roots for de novo synthesis of different classes of lipophilic compounds. These experiments have shown, for example, that in the mature parts of roots (the rest remaining after cutting off 1 -cm-long tips), the inhibition of biosynthesis of compounds belonging, probably, to free sterols or free fatty acids, is not restored with the time of treatment. As the amount of free fatty acids in the extracts is usually small, it should be considered that the observed inhibition concerns mainly free sterols. The other significant difference observed between the control and the cerulenin-treated plants was a very strong inhibition (which did not disappear with time of treatment) of the biosynthesis of an unidentified lipid, $\mathrm{Y}_{2}$, probably cardiolipin. It remains unknown whether the inhibition of the biosynthesis of this compound has a significant role in the phytotoxic effects of cerulenin on the treated plants. However, if the $\mathrm{Y}_{2}$ lipid is cardiolipin (it was identified only by means of a co-chromatographed standard), the inhibition of its biosynthesis could cause significant disturbances in mitochondrial functions, as cardiolipin plays a crucial role in the functioning of these organelles (Christie, 2012). One cannot exclude that cardiolipin may also be involved in hexokinase II function. This protein plays a protective role in preservation of mitochondrial integrity, and it has recently been shown that cerulenin may affect its association with mitochondrial membranes in cancer cells, and thereby cause death of those cells (Jeong \& Yoo, 2012). So far, no such effects have been demonstrated in plants. However, Kim et al (2006), after silencing the gene coding hexokinase I (associated with mitochondria) in Nicotiana benthiana, observed symptoms of programmed death in transformed cells.

A strong increase in the de novo biosynthesis of PE was one of the other significant changes in the biosynthesis of lipophilic compounds, caused by the treatment of the tested grass species with haloxyfop and cerulenin. A similar increase in the biosynthesis of PE occurs in plants exposed to cold (Steponkus et al, 1990; Palta et al, 1993) and is regarded as one of the mechanisms of the plants' acclimation to sub-zero temperatures. Whether the increase in PE synthesis in plants treated with the investigated inhibitors is an adaptive mechanism, or one of the causes of phytotoxic effects, remains unanswered. However, the fact that these changes occur only after a longer treatment may suggest the former.

In conclusion, it seems reasonable to suggest that inhibition of fatty acid biosynthesis is probably not the only (or maybe not even the main) reason of haloxyfop and cerulenin phytotoxicity. The results obtained for haloxyfop and the data from earlier experiments suggest that in order to explain its mechanism of action both competing hypotheses (the anabolic one, pointing to inhibition of fatty acid biosynthesis, and the catabolic one, postulating "oxidative stress" as the cause of plant death - see Introduction) should be considered. In the case of cerulenin's phytotoxic mode of action, at least its multidirectional effects on lipid metabolism (containing and not containing fatty acids) should be taken into account.

\section{Acknowledgements}

This work was supported partially by KBN, grant no. 6 PO4C 072 12. The authors would also like to thank Professor Sten Stymne from the Swedish University of Agricultural Science for his comprehensive help throughout this research. 


\section{REFERENCES}

Banaś A, Johansson I, Stenlid G, Stymne S (1990) The effect of haloxyfop-ethoxyethyl on lipid metabolism in oat and wheat shoots. Swedish J Agric Res 20: 97-104.

Banaś A, Johansson I, Stenlid G, Stymne S (1993a) Free radical scavengers and inhibitors of lipoxygenases as antagonists against the herbicides haloxyfop and alloxydim. Swedish J Agric Res 23: 67-75.

Banaś A, Johansson I, Stenlid G, Stymne S (1993b) The effect of haloxyfop and alloxydim on growth and fatty acid composition of wheat roots. Swedish J Agric Res 23: 55-65.

Banaś A, Johansson I, Stenlid G, Stymne S (1993c) Investigation of the mode of action of the herbicide haloxyfop. Zesz Nauk Wyższ Szk Roln P Siedlce Ser Nauki Prsyrodnicze 34: 1-19.

Bligh EG, Dyer WJ (1959) A rapid method of total lipid extraction and purification. Can J Bioch Physiol 37: 911-917.

Cobb A (1992) Herbicides and Plant Physiology. pp 107-125. Chapman and Hall, London.

Christie WW (2012) Cardiolipin (diphosphatidylglycerol) — structure, occurrence, biology and analysis. http://lipidlibrary.aocs.org/lipids/

De Prado JL, De Prado RH, Shimabukuro RH (1999) The effect of diclofop on membrane potential, ethylen induction, and herbicide phytotoxicity in resistant and susceptible biotypes of grasses. Pestic Biochem Physiol 63: 1-14.

Feld A, Kobek K, Lichtenthaler HK (1989) Inhibition of fatty acid biosynthesis in isolated chloroplasts by the antibiotics cerulenin and thiolactomycin. Brighton Crop protection Conf - Weeds 1989, pp 479486.

Harwood JL (1999) Graminicides which inhibit lipid synthesis. Pesticide Outlook, pp 154-158.

Heap IM, Morrison IN (1996) Resistance to aryloxyphenoxypropionate and cyclohexanedione herbicides in green foxtail (Setaria viridis). Weed Sci 44: 25-30.

Herbert D, Walker KA, Price LJ, Cole DJ, Pallett KE, Ridley SM, Harwood JL (1997) Acetyl-CoA carboxylase — a graminicide target site. Pestic Sci 50: 67-71.

Hoppe HH (1985) Differential effect of diclofop-methyl on fatty acid biosynthesis in leaves of sensitive and tolerant plant species. Pesticide Biochem Physiol 23: 297-302.

Jeong NY, Yoo YH (2012) Cerulenin-induced apoptosis is mediated by disrupting the interaction between AIF and hexokinase II. Int J Onkol 40: 1949-1956.

Kim M, Lim JH, Ahn ChS, Park K, Kim GT, Kim WT, Pai HS (2006) Mitochondria-associated hexokinases play a role in the control of programmed cell death in Nicotiana benthamiana. The Plant Cell 18: 2341-2355.
Lichtenthaler H (1990) Mode of action of herbicides affecting acetylCoA carboxylase and fatty acid biosynthesis. Zeitschr $f$ Naturforsch 45c: 521-528.

Luo XY, Sunohara Y, Matsumoto H (2004) Fluazifop-butyl causes membrane peroxidation in the herbicide-susceptible broad leaf weed bristly starbur (Acanthospermum hispidum). Pestic Biochem Physiol 78: 93-102.

Nestler HJ (1982) Phenoxy-phenoxypropionic acid derivatives and related compounds. In Chemie der pflanzenscchutz und schädling-sbekämpfungsmittel Wegler R, ed, pp 1-25. Springer-Verlag, Berlin.

Nilsson G (1977) Effects of glyphosate on the amino acid content in spring wheat plants. Swedish J Agric Res 7: 135-157.

Packter NM, Stumpf PK (1975) Fat metabolism in higher plants. The effect of cerulenin on the synthesis of medium- and lon-chin acids in leaf tissue. Arch Bioch Biophys 167: 655-667.

Palta JP, Whitaker BD, Weiss LS (1993) Plasma membrane lipids associated with genetic variability in freezing tolerance and cold acclimation of Solanum species. Plant Physiol 103: 793-803.

Price LJ, Herbert D, Cole DJ, Harwood J (2003) Use of plant cell cultures to study graminicide effects on lipid metabolism. Phytochemistry 63: $533-541$.

Rendina AR, Felts JM, Beaudoin JD, Craig-Kennard AC, Look LL, Paraskos SL, Hagenah JA (1988) Kinetic characterisation, stereoselectivity, and species selectivity of the inhibition of plant acetyl-CoA carboxylase by aryloxyphenoxypropionic acid grass herbicides. Arch Biochem Biophys 265: 219-225.

Roughan PG, Slack CR (1982) Cellular organisation of glycerolipid metabolism. Annu Rev Plant Physiol 33: 97-132.

Shimabukuro RH, Davis DG, Hoffer BL (2001) The effect of diclofop-methyl and its antagonist, vitamin E, on membrane lipids in oat (Avena sativa L.) and leafy spurge (Euphorbia esula L.). Pestic Biochem Physiol 69: 13-26.

Shimabukuro RH, Hoffer BL (1996) Induction of ethylene as an indicator of senescence in the mode of action of diclofop-methyl. Pestic Biochem Physiol 54: 146-158.

Shukla A, Dupont S, Devine MD (1997) Resistance to ACCase-inhibitor herbicides in wild oat: Evidence for target site-based resistance in two biotypes from Canada. Pestic Biochem Physiol 57: 147-155.

Steponkus PL, Lynch DV, Uemura M (1990) The influence of cold acclimation on lipid composition and cryobehaviour of plasma membrane of isolated rye protoplasts. Phil trans R Lond B 326: 572-583.

Tardif FJ, Preston C, Holtum JA, Povles SB (1996) Resistance to acetyl-coenzyme A carboxylase- inhibiting herbicides endowed by a single major gene encoding a resistant target site in biotype of Lolium rigidum. Aust J Plant Physiol 23: 15-23. 